\title{
Estranhamentos na pesquisa bibliográfica: invenção cartográfica na busca sistemática
}

\author{
Strangeness in bibliographic research: \\ cartography invention in systematic search \\ Extrañeza en la investigación bibliográfica: \\ invenciones cartográficas en la búsqueda sistemática
}

\author{
Simone Mainieri Paulon ${ }^{2}$ \\ Ariadne Cedraz de Cerqueira ${ }^{3}$ \\ Fernanda Goulart Martins ${ }^{4}$
}

Resumo: O objetivo deste artigo é descrever e analisar os procedimentos de uma pesquisa bibliográfica realizada por pesquisadores implicados. Apoiada na ética do "transformar para conhecer" a investigação contou com um processo didaticamente dividido em quatro etapas: construção de procedimento para busca de conteúdos; seleção dos conteúdos encontrados; estudo crítico-analítico dos dados obtidos e sua sistematização. Diverso às pesquisas bibliográficas tradicionais, as etapas descritas no artigo não foram estabelecidas a priori, mas se delinearam ao longo do processo investigativo. Isto revela o diferencial do estudo: uma pesquisa bibliográfica de inspiração cartográfica que opera o princípio da inversão metodológica de um hódos-metá, no qual as metas são definidas ao caminhar e não são antecipadas ao percurso. Conclui-se que, mesmo nos procedimentos aparentemente padronizados, como é o caso da busca sistemática, um processo de pesquisa sempre reserva espaço à invenção.

Palavras-chave: Metodologia. Revisão de Literatura. Invenção.

Abstract: The aim of this article is to describe and analyze the procedures of a bibliographic research carried out by researchers involved. Based on the ethics of "transforming to know" the research counted on a process divided into four steps: construction of a procedure to search for content; selection of content found; criticalanalytical study of the data obtained and its systematization. Countering the traditional bibliographic research, the steps described in the article were not established a priori, but were delineated throughout the investigative process. This reveals the differential of the study: a bibliographical research of cartographic inspiration that operates the principle of the methodological inversion of a hodos-meta. In this proposition, the goals are defined when walking and are not anticipated to the research course. It is concluded that, even in apparently standardized procedures, as in the case of systematic search, a research process always reserves space for invention.

Keywords: Methodology. Literature Review. Invention

Resumen: El objetivo de este artículo es describir y analizar los procedimientos de una investigación bibliográfica realizada por investigadores implicados. Apoyada en la ética del "transformar para conocer" la investigación contó con un proceso didáctico dividido en 4 etapas: construcción de procedimiento para búsqueda de contenidos; selección de los contenidos encontrados; estudio crítico-analítico de los datos obtenidos y su sistematización. Diverso a las investigaciones bibliográficas tradicionales, las etapas descritas no se establecieron a priori, pero se delinearon a lo largo del proceso. Esto revela el diferencial del estudio: una investigación bibliográfica de inspiración cartográfica que opera el principio de la inversión metodológica de un hodos-meta, en el cual las metas se definen al caminar y no se adelantan al percorrido. Se concluye que, incluso en los procedimientos aparentemente estandarizados, como es el caso de la búsqueda sistemática, un proceso de investigación siempre reserva espacio a la invención.

Palabras clave: Metodología. Revisión de Literatura. Invención.

\footnotetext{
${ }^{1}$ Submetido em: 20 dez. 2018 - Aceito em: 20 jun. 2019 - Publicado em: 25 nov. 2019

${ }^{2}$ Universidade Federal do Rio Grande do Sul (UFRGS) - E-mail: simonepaulon@ gmail.com

${ }^{3}$ Universidade Federal do Rio Grande do Sul (UFRGS) - E-mail: dinecedraz@ yahoo.com.br

${ }^{4}$ Universidade Federal do Rio Grande do Sul (UFRGS) - E-mail: fernandamartinsfm@ @otmail.com
} 


\section{Introdução}

Debruçar-se sobre um problema, a fim de produzir conhecimento, é, em última instância, germinar realidades. Todavia, embora aqui se demarque o caráter inventivo da ciência, de modo a reconhecer nela certa vitalidade (CANGUILHEM, 2012), é preciso indicar que as produções científicas se processam em meio a estudos e práticas imbuídos de uma "ética do conhecimento acadêmico", reafirmando a necessidade de rigor na produção de conhecimento.

Assim sendo, é esperado que todo escrito que materializa a produção acadêmica conte com um texto de fundamentação teórica e que, de forma mais evidente ou de modo diluído, ele apresente conceitos e ou concepções de mundo que demonstrem as bases elementares para o que se quer expressar. Nesse sentido, a revisão de literatura é uma etapa fundamental do trabalho acadêmico, chegando a ser indicada como lastro para a redação científica. Ela pode ser: narrativa, sistemática ou integrativa (FERENHOF; FERNANDES, 2016).

A revisão narrativa deriva de uma "[...] pesquisa por conveniência e sem artefatos objetivos de seleção do material” (MARIANO; SANTOS, 2017, p. 431). Sendo, por conseguinte, uma revisão exploratória, na qual a seleção de conteúdo é arbitrária e não tem o objetivo de esgotar as informações existentes sobre o assunto (FERENHOF; FERNANDES, 2016).

A revisão sistemática tem como principal característica um rigor metodológico com etapas pré-estabelecidas. Tal modalidade de revisão se vale de critérios de seleção claramente explicitados para a escolha do seu material. Isso é feito na intenção de reduzir a possibilidade de erro na escolha dos textos utilizados. Estão sempre envolvidos mais de um pesquisador, de modo que todos devem ler todo material com o qual se deparam e, após discussão, decide-se qual conteúdo deverá compor o texto da revisão. Nesse tipo de revisão são buscados estudos primários relacionados a uma questão específica, dos quais serão extraídos os dados para a construção de uma síntese das informações encontradas. Tal síntese pode ser analisada de forma narrativa ou estatística (FERENHOF; FERNANDES, 2016; MARIANO; SANTOS, 2017).

A revisão integrativa, por sua vez, também se dá de modo planejado. Do mesmo modo que a revisão sistemática, ela conta com uma busca sistemática de material, assumindo uma investigação que, por meio de um planejamento bem estruturado, intenta eliminar vieses. Diferentemente da revisão sistemática, que foca estudos primários, a revisão integrativa pode ter um propósito limitado ou amplo, considerando, por exemplo, dados da literatura teórica e outros tipos de pesquisas. Então, ela visa, por meio de métodos explícitos e sistemáticos, sintetizar resultados e lançar novas perspectivas (FERENHOF; FERNANDES, 2016; MARIANO; SANTOS, 2017).

Assim como Ferenhof e Fernandes (2016) fazem questão de demarcar a diferença entre a revisão sistemática e a busca sistemática (a qual é parte da revisão integrativa), Lima e Mioto (2007) consideram essencial assinalar a diferença entre a revisão bibliográfica e a pesquisa bibliográfica. Para estas autoras, a revisão bibliográfica (ou revisão de literatura) constitui-se pré-requisito para toda pesquisa, qualquer que seja; enquanto que a pesquisa bibliográfica se 
define como sendo "um conjunto ordenado de procedimentos de busca por soluções atento ao objeto de estudo e que, por isso, não pode ser aleatório" (LIMA; MIOTO, 2007, p. 38). Logo, enquanto a revisão é parte de uma pesquisa, a pesquisa bibliográfica é uma pesquisa em si mesma. Logicamente, isto não impede que uma pesquisa bibliográfica forneça elementos para uma revisão de literatura.

Dito isto, esclarecemos que o presente artigo apresenta o percurso de uma pesquisa bibliográfica, realizada ao longo de dois anos, a qual fornece sustentação aos estudos de um grupo de pesquisa e conteúdo para revisões de literatura em produções futuras. Com objetivo de compartilhar uma experiência inventiva de cumprir uma etapa via de regra protocolar dos estudos acadêmicos e apontar alguns de seus resultados, o presente artigo propõe-se a relatar a experiência de uma pesquisa bibliográfica, apoiada sobre uma ética do "transformar para conhecer" a qual não toma a realidade como algo já dado, que existe anterior ao trabalho do pesquisador, mas como um campo que se anuncia no ato da pesquisa e se relança a todo momento.

Para fazê-lo será importante uma contextualização do grupo que protagonizou a experiência, seus fundamentos e modos de trabalhar; seguida de um detalhamento acerca das bases e procedimentos da pesquisa bibliográfica, tal como realizada pelo grupo, para finalmente apontar os efeitos que este trabalho assumiu no processo investigativo em que está inserido.

\section{Grupo intervires e seu modo de pesquisar intervindo}

O grupo INTERVIRES ${ }^{i}$ é um Grupo de Estudos, Pesquisas, Invenções e Intervenções no campo da saúde coletiva, das cidades, das políticas de saúde mental e políticas de subjetividade contemporânea. Ele está vinculado ao Programa de Pós-Graduação de Psicologia Social e Institucional da Universidade Federal do Rio Grande do Sul e, desde 2008, dedica-se à experimentação entre métodos, numa perspectiva transdisciplinar.

Em decorrência de muitos de seus estudos no campo da saúde mental e saúde coletiva se relacionarem aos debates sobre espaços públicos, políticas públicas e modos de governar, em meados de 2016, o grupo passou a se interessar de forma precípua por estudos da cidade. Em 2017, a pesquisa "Experiências Urbanas e Produção do Comum: modos de vida e invenção das cidades em tempos de intolerância" ii foi iniciada com o objetivo de analisar a diversidade dos modos de vida que compõem a experiência urbana, acompanhando os processos de exclusão e resistência de diferentes grupos na cidade de Porto Alegre.

O desafio inicial que se colocou aos pesquisadores foi o de compreender como a cidade é vista nos artigos científicos e para quem tal cidade é projetada. Foi isto que delineou uma pesquisa bibliográfica que tomasse como foco as noções de cidade e subjetividade, considerando a indissociabilidade entre os dois conceitos.

Consideramos que a produção de conhecimento científico por meio da pesquisa bibliográfica é uma prática que implica a delimitação de critérios que determinam procedimentos metodológicos, para tornar possível a busca de soluções para um problema de pesquisa ou complexificar um campo problemático (LIMA; MIOTO, 2007). No processo de 
pesquisar, "[...] o delineamento metodológico [...] tende a ser a parte mais delicada, difícil e, por vezes, arrasadora de qualquer estudo" (MAURENTE, 2015, p. 109), pois uma escolha diante da multiplicidade de métodos significa o aborto de tantas outras possibilidades.

Se por um lado, como diz Maurente (2015), a escolha de uma estratégia metodológica cala certas possibilidades, por outro, anuncia uma escolha epistemológica, enunciando não somente uma visão de mundo, mas também uma relação com o próprio conhecimento. Por conseguinte, advogamos que, tanto a compreensão de como opera um conceito e uma perspectiva teórica, quanto o modo como se compõe a investigação no campo de pesquisa, são determinantes na escolha de um método que possibilite a pesquisa bibliográfica.

A máxima do "transformar para conhecer" (BARROS, 1997, p. 189) tomada da crítica à instituição pedagógica formulada pelo institucionalismo francês, demarca o modo INTERVIRES de se movimentar em campo, assumindo que a produção de conhecimento não revela sentidos, mas cria sentidos. Não há separação entre a pesquisa e a intervenção, portanto, qualquer intervenção modula as ações do campo de pesquisa e é o processo de transformação de uma realidade que imprime a possibilidade de produzir conhecimento sobre a mesma (BARROS, 1997; PASSOS; BARROS, 2015).

Embora exista toda uma literatura de metodologia científica que indica modos de fazer pesquisa bibliográfica, a pesquisa aqui narrada não seguiu nenhuma das estratégias prédeterminadas. A pesquisa bibliográfica do grupo INTERVIRES foi conduzida em um processo que ocorreu a partir dos pressupostos da cartografia.

Passos, Kastrup e Escóssia (2015), na apresentação do livro "Pistas do método cartográfico", demarcam que a cartografia descende diretamente do conceito de rizoma, desenvolvido por Deleuze e Guattari. Assim sendo, a cartografia refere-se a um modo de fazer pesquisa que não pode ser desconectada de um sistema acêntrico - o rizoma não tem centro. Deste modo, a cartografia se insere como uma diretriz que não impõe direção pré-determinada, uma vez que na lógica do rizoma toda linearidade se desfaz, não há um início ou um fim, há possibilidades. Posto isto, os autores dizem:

\begin{abstract}
A metodologia, quando se impõe como palavra de ordem, define-se por regras previamente estabelecidas. Daí o sentido tradicional de metodologia que está impresso na própria etimologia da palavra: metá-hódos. Com essa direção, a pesquisa é definida como caminho (hódos) predeterminado pelas metas dadas de partida. Por sua vez, a cartografia propõe uma reversão metodológica: transformar metá-hódos em hódos-metá. Essa reversão consiste numa aposta na experimentação do pensamento - um método não para ser aplicado, mas para ser experimentado e assumido como atitude (PASSOS; KASTRUP; ESCÓSSIA, 2015, p. 10-11, grifo do original).
\end{abstract}

Perscrutando um caminho de experimentação contínua, o grupo INTERVIRES entendeu ser possível e desejável fazer da inversão metodológica, proposta pela cartografia, um princípio orientador da pesquisa bibliográfica. Construiu, a partir daí, um idiossincrático movimento de desenvolver o passo a passo de uma pesquisa bibliográfica que, ao longo do seu próprio desenrolar, ia negociando critérios das próximas escolhas teóricas e estabelecendo modos de funcionamento do grupo de pesquisadores para os estudos subsequentes.

É sabido que, na produção de conhecimento científico, costuma-se fazer uma revisão de literatura para conhecer as principais linhas de pesquisa que se voltam a um determinado 
campo problemático (MARIANO; SANTOS, 2017). Não é esta, por óbvio a originalidade do percurso pesquisante que o presente artigo propõe examinar. O que aqui se está a enfatizar é que, embora os princípios de evitar hipóteses ou partir de pressupostos teóricos acerca do problema de pesquisa não fossem novidades para o grupo de pesquisa, foi uma experiência inusitada para o grupo INTERVIRES levar a cabo tal proposta numa pesquisa bibliográfica. Sendo assim, propusemo-nos a realizar uma busca sistemática por material de leitura, que constituiu uma pesquisa bibliográfica, na qual o método foi coletivamente construído enquanto se dava o próprio percurso de investigação.

Passaremos agora ao detalhamento dos procedimentos pelos quais esta experimentação se construiu.

\section{Construindo um processo de revisão bibliográfica}

A fim de fornecer bases para pensar a produção de subjetividade e as experiências urbanas que promovem a produção do comum como modo de resistência ao capitalismo contemporâneo, a pesquisa bibliográfica foi sustentada na inversão metodológica proposta pelo método cartográfico (PASSOS; KASTRUP; TEDESCO, 2014; PASSOS; KASTRUP; ESCÓSSIA, 2015). Desenrolou-se ao longo de dois anos e delineou-se em três etapas, que passamos a descrever.

\subsection{Etapa 1}

Teve como objetivo encontrar artigos científicos que pudessem apresentar o modo pelo qual os estudos sobre cidades, em sua interface com o conceito subjetividade, têm sido apresentados no contexto dos artigos científicos. Tal etapa consistiu na escolha de bases de dados ( $1^{\mathrm{a}}$ fase); escolha de descritores e testagem dos descritores escolhidos ( $2^{\mathrm{a}}$ fase); busca de artigos e organização dos artigos encontrados ( $3^{\mathrm{a}}$ fase).

\subsection{1) $1^{\mathrm{a}}$ Fase: Escolha das bases de dados}

Nas discussões sobre onde buscar conteúdos, defendeu-se a necessidade de que a pesquisa se valesse de plataformas que contemplassem artigos de diferentes locais do mundo. Vale, entretanto, destacar que, embora se desejasse conhecer produções variadas, o grupo tinha especial interesse em produções científicas de língua latina, dada as aproximações à realidade brasileira. O consenso em relação às plataformas foi possível ao passo que os critérios de escolha foram alvo de amplo debate. Scopus e Scielo foram bases de dados escolhidas pelo fato de que ambas têm um número significativo de periódicos que abrangem a problemática em foco. Além disso, a Scopus é indicada como um dos bancos de dados mais importantes (MARIANO; SANTOS, 2017), reúne periódicos de diferentes lugares do mundo, é uma base internacionalmente reconhecida, com alternativas de acesso pago e gratuito. A Scielo, por sua vez, dispõe todo acesso gratuito, sendo criteriosa - à época da pesquisa, dispondo apenas de 1200 periódicos em sua base -, essencialmente, latino-americanos.

3.1.2) $2^{\mathrm{a}}$ Fase: Escolha e testagem de descritores 
O ponto de partida para a escolha dos descritores a serem usados veio das palavraschave mais importantes da pesquisa-matriz, a saber: Cidade e Subjetividade. Dada a polifonia dos termos, e as leituras iniciais e prévias já feitas pelo grupo de pesquisadores, logo se entendeu que as referidas palavras-chave abarcariam um número elevado de artigos (próximo a 1200 nos ensaios feitos com eles). Passou-se então à escolha de quais termos descendiam dos dois descritores originais e como cruzá-los para proceder à pesquisa bibliográfica. Inicialmente, os descritores escolhidos, em duas famílias temáticas, foram: Subjetividade, subjetivação, alteridade, singularidade e, no segundo grupo: cidade, urbana, urbano, polis e cidadania.

Corroborando a ideia de que o termo escolhido para uma busca de artigos em bases de dados é um fator que pode alterar os resultados de pesquisa (MARIANO; SANTOS, 2017), vários testes foram realizados para validar a escolha dos descritores. Nesta crucial fase de testagem dos descritores, o termo cidadania foi excluído, uma vez que ampliava enormemente o volume de leituras com artigos muito distantes do foco da pesquisa-matriz. Observou-se, também, que os termos Cidade e Subjetividade apareciam em outras combinações de descritores nas quais o termo cidadania não constava, o que fundamentou a decisão de sua exclusão. Assim, procedeu-se à busca por textos por meio de duas famílias de descritores, cada uma composta de quatro palavras que descendiam de cada descritor original. A combinação cruzada (com AND) entre os descritores, formou 16 combinações, uma vez que cada um dos descritores da primeira família foi cruzado com cada um dos descritores da segunda família. Por exemplo: Subjetividade and cidade; subjetividade and urbana; subjetividade and urbano; Subjetividade and polis; Subjetivação and cidade; subjetivação and urbano e, assim, sucessivamente, até os descritores das duas famílias temáticas se esgotarem.

3.1.3) $3^{\text {a }}$ Fase: Busca de artigos e organização de artigos encontrados

O conjunto de artigos que resultou das 16 buscas na plataforma Scielo, somado ao conjunto de artigos resultantes das 16 buscas feitas na plataforma Scopus, resultou em 753 artigos -186 da plataforma Scielo e 567 da Scopus. Considerando o número de artigos obtidos nesta etapa da pesquisa, resolveu-se, primeiramente, fazer uma leitura dos resumos de tais artigos encontrados. De forma que, excluindo-se os artigos repetidos nas duas bases de dados, foram lidos 562 resumos, o que constitui a segunda etapa da pesquisa bibliográfica aqui descrita.

\subsection{Etapa 2}

Com o objetivo de selecionar os artigos que, definitivamente, comporiam o conjunto de leituras e serviriam de base para os estudos e possíveis produções acadêmicas da pesquisamatriz, esta etapa consistiu na criação de perguntas balizadoras para leitura e avaliação de resumos, a fim de estabelecer uma seleção de artigos ( $1^{\text {a }}$ fase); reavaliação de resumos filtrados na primeira fase ( $2^{\mathrm{a}}$ fase); avaliação da filtragem realizada e criação de nova pergunta balizadora para reavaliação dos resumos e sua categorização em eixos temáticos ( $3^{\mathrm{a}}$ fase).

3.2.1) $1^{\text {a }}$ Fase: Criação de perguntas balizadoras, leitura e avaliação de resumos

Os 562 resumos dos artigos selecionados na etapa anterior foram lidos pelo grupo de pesquisadores, considerando 4 perguntas balizadoras. A intenção era estabelecer critérios para 
incluir e para excluir artigos na lista de leituras. As perguntas balizadoras serviram de parâmetros para valorar os artigos a partir da sua conexão com os temas-foco da pesquisamatriz. Para tanto, cada pergunta gerava uma pontuação específica que possibilitasse priorizar a importância dos artigos, caso a leitura de seu resumo permitisse respondê-la. As quatro perguntas balizadoras e sua valência em pontos usadas nesta etapa foram:

- O resumo se refere a Processos de Subjetivação? (4 pontos);

- O resumo traz uma percepção das cidades para além da compreensão estritamente voltada para os equipamentos e espaços localizados? Os conceitos devem remeter diretamente à cidade, mas não em sua literalidade necessariamente (3 pontos);

- O resumo aponta para o modo de relação do sujeito com a cidade (hegemonicamente ou contra-hegemonicamente)? (2 pontos);

- O resumo apresenta ferramentas teórico-metodológicas para pensar a cidade para além do espaço geográfico? (1 ponto).

Assim, se após leitura do resumo o pesquisador percebesse que o artigo respondia positivamente à primeira pergunta, o artigo era pontuado com 4 pontos; se pontuado com 3 pontos indicava que o artigo responderia à segunda pergunta, sucessivamente, quando respondia positivamente à quarta pergunta, o resumo recebia 1 ponto.

Há muita produção de conhecimento acerca do processo de seleção de material para compor tanto as pesquisa bibliográficas quanto a revisão de literatura (FERENHOF; FERNANDES, 2016; LIMA; MIOTO, 2007; MARIANO; SANTOS, 2017). Apesar disso, é mister indicar que esta estratégia de inclusão/exclusão de artigos a serem lidos na íntegra foi construída no coletivo de pesquisa envolvido, contando com vários processos de testagem e lapidação das questões norteadoras. As quatro questões foram elaboradas com o objetivo de encontrar, entre os artigos (advindos pela busca realizada na etapa anterior), escritos que pudessem indicar qual(is) cidade(s) - e que cidade(s) para quem - tem sido objeto de investigação nas publicações feitas na América Latina, considerando a perspectiva conceitual assumida pelo grupo de pesquisa INTERVIRES.

Nesse sentido, foi imprescindível realizar, a cada etapa dessa pesquisa bibliográfica, o exercício de parar o processo e rever o modo com que se estava buscando as leituras. Tal procedimento era conduzido a partir das discussões e novos questionamentos disparados pelas próprias leituras feitas no percurso. A cada etapa da pesquisa bibliográfica aqui descrita, portanto, inventava-se um jeito de pesquisar, sempre atento aos objetivos propostos.

Esse procedimento parece ter estreita relação com a flexibilidade da pesquisa bibliográfica demarcada por Lima e Mioto (2007), quando discorrem acerca do procedimento metodológico em estudos exploratório-descritivos. No entanto, as autoras afirmam que tal flexibilidade "[...] não significa descompromisso com a organização racional e eficiente frente à tarefa [...]" (LIMA; MIOTO, 2007, p. 40). A flexibilidade no processo inventivo aqui descrito, envolve perguntas coletivamente construídas durante o proceder da pesquisa, compondo o movimento investigativo para afirmar nele seu rigor metodológico. No percurso da pesquisa bibliográfica do grupo INTERVIRES, as inúmeras testagens das perguntas que nortearam o processo de seleção de artigos e o processo contínuo de avaliação dos 
procedimentos a cada etapa da pesquisa foram fundamentais para que a produção de conhecimento se fizesse de modo rigoroso e técnico. Também fez parte das escolhas que compuseram os procedimentos de pesquisa, o fato de todos os resumos terem sido lidos por dois pesquisadores distintos, que não se comunicavam a respeito das impressões que tinham da leitura realizada.

\subsection{2) $2^{\text {a }}$ Fase: Reavaliação de resumos filtrados}

Houve casos em que se deu discordância entre as avaliações feitas pelos dois leitores. Por conseguinte, nesta fase da $2^{\mathrm{a}}$ etapa da pesquisa bibliográfica, o grupo designou um terceiro leitor (que ainda não lera nenhum dos artigos com avaliações discordantes) para funcionar como um juiz cego que avaliava - usando as mesmas 4 perguntas balizadoras -, se o texto comporia ou não a lista de artigos a serem lidos na íntegra. Foram excluídos os artigos cujos resumos foram pontuados com menos de cinco pontos por dois leitores.

3.2.3) $3^{a}$ Fase: Avaliação da filtragem, criação de nova pergunta balizadora, reavaliação e categorização dos resumos

Após as fases anteriores, restaram 236 artigos. Mais importante que o fato de os pesquisadores ainda conceberem que tal número era muito elevado, eles indicavam que - pela leitura dos resumos - havia um volume grande de artigos que traziam questões pouco caras à temática estudada e à perspectiva teórica assumida pelo grupo de pesquisa. Assim, o grupo concluiu que ainda era necessário criar mais um recurso para aprimorar a seleção do material.

Então, por meio de discussões entre os pesquisadores, valendo-se de testagens feitas com alguns resumos aleatoriamente escolhidos, foi elaborada mais uma questão balizadora. Deste modo, os resumos com pontuação igual ou maior que 5 foram relidos pelos pesquisadores, na intenção de responder a seguinte pergunta: $\mathrm{Na}$ abordagem do artigo, a cidade/o espaço/o território opera ou produz processos de subjetivação? Os artigos que tiveram resposta positiva para esta última pergunta foram selecionados para serem lidos na íntegra.

Enfim, foram selecionados 107 artigos, os quais foram categorizados em eixos temáticos, a fim de melhor organizar os estudos. Os eixos temáticos foram criados a partir das leituras dos resumos e validados pelos integrantes do grupo de pesquisa. Ao final desta etapa, os 107 artigos restantes foram agrupados a partir dos conteúdos que continham e distribuídos entre onze eixos temáticos: Arquitetura e urbanismo; Arte e mídia; Contexto rural; Corpo e cidade; Cuidado na rede de saúde; Gênero e sexualidade; Imigração e fronteiras territoriais; Infância e juventude; Medo e violência; Relações étnico-raciais, afro-brasileiras e indígenas; Trabalho e relações produtivas na cidade.

\subsection{Etapa 3}

Teve como objetivo promover o estudo em grupo dos artigos encontrados nas etapas anteriores deste processo, além de criar estratégias de facilitar a recuperação dos textos para uso dos mesmos em revisões de literatura futuras pertencentes aos relatórios de pesquisa, artigos científicos ou demais materiais do gênero. 
Tal etapa consistiu na construção de um modelo de ficha de leitura, além da leitura e fichamento dos textos ( $1^{\mathrm{a}}$ fase); apresentação dos textos em sessões de debate entre os pesquisadores, criação de tags e tagueamentos dos fichamentos ( $2^{\mathrm{a}}$ fase $)$; inserção das fichas de leituras em software de pesquisa qualitativa e sumarização das questões debatidas no processo de estudo ( $3^{\text {a }}$ fase).

\subsection{1) $1^{\text {a }}$ Fase: Construção de ficha de leitura, leitura e fichamento dos artigos}

Nesta fase da terceira etapa, cada pesquisador encarregou-se de ler um determinado número de artigos, fichá-los e apresentar a leitura para os demais integrantes do grupo de pesquisa. Para tanto, foi discutido e definido um modelo de fichamento a ser adotado pelo grupo. Foi importante considerar, desde o modo como cada arquivo - artigos encontrados na pesquisa e seu respectivo fichamento - deveria ser nomeado (uma vez que tais arquivos passariam a compor a biblioteca virtual do grupo), até os passos a serem seguidos pelos pesquisadores para confeccionar sua ficha de leitura.

Alguns autores defendem que o fichamento é uma fase importante da pesquisa bibliográfica, e indicam que ele deve apresentar, principalmente, um resumo da obra lida e a bibliografia da mesma, chegando a fornecer modelos que possam auxiliar pesquisadores e estudantes (MARCONI; LAKATOS, 2007). Entretanto, assim como o processo de pesquisa foi elaborado de modo singular nessa investigação, o modelo de fichamento assumido no grupo INTERVIRES foi desenvolvido pelo próprio grupo de pesquisa, considerando as necessidades implicadas nesse estudo e a peculiaridade da pesquisa em questão.

Considerando o processo de confecção da ficha de leitura, inicialmente, ela era composta por: 1) Referência do artigo e o seu link para acesso; 2) Ideia central do texto em uma frase do autor da ficha e palavras-chave; 3) Espaço para uma análise ou comentários críticos considerados importantes para a pesquisa-matriz; e, 4) Citações literais do artigo, considerando o contexto da pesquisa-matriz.

Posteriormente (quando se vivenciava a segunda fase desta terceira etapa), o grupo considerou relevante acrescentar dois outros itens: 5) Identificação do autor da ficha; e, 6) Metodologia de pesquisa utilizada no artigo lido.

3.3.2) $2^{a}$ Fase: Apresentação dos textos, criação de tags e tagueamento dos fichamentos

As apresentações dos artigos lidos deram-se com base nos eixos temáticos estabelecidos na etapa anterior. Durante os debates advindos da leitura dos 107 artigos, os pesquisadores perceberam que alguns temas se repetiam em diversos estudos, e identificaram, nos textos selecionados, colocações a respeito de determinados autores, importantes citações que costumam compor os referenciais teóricos das pesquisas do grupo, diferentes formas de conceituar a cidade, bem como a presença de temas outros (drogas, racismo, gênero, turismo etc.), discutidos de modo articulado à cidade.

Daí surgiu a ideia de desenvolver uma estratégia que pudesse oportunizar a identificação de tais temáticas (citações, conceitos, abordagens etc.) nos fichamentos, de modo a favorecer e facilitar a construção de textos de revisão de literatura, recuperando o conteúdo proveniente da pesquisa bibliográfica realizada pelo grupo. 
A partir então, do que se percebia nos textos encontrados na pesquisa bibliográfica, foram coletivamente construídas tags, as quais funcionariam como uma espécie de etiqueta/código ou categorização temática de conteúdo encontrado no artigo. Tais tags tinham por objetivo possibilitar a recuperação de informações/conteúdos, quando do momento de escrita de relatórios ou demais textos científicos resultantes da pesquisa-matriz. Deste modo, cada fichamento foi tagueado pelo autor da ficha de leitura e novamente revisitado (para novo tagueamento) se, em algum momento, uma outra tag surgia.

Para garantir que os pesquisadores entendiam claramente o que significava cada tag, foram feitos inúmeros exercícios de tagueamento em grupo. Isso acontecia, por exemplo, quando um pesquisador levava a sua ficha de leitura para o grupo e todos liam juntos o texto; às vezes, discutia-se o conteúdo articulando-o às tags já consolidadas pelo grupo; às vezes, ressignificava-se uma tag já consolidada, ampliando o significado deste código; outras vezes, criava-se novas tags a partir do conteúdo debatido. Tal exercício coletivo serviu tanto como um movimento de estudo pertinente ao processo de pesquisa bibliográfica, quanto como um procedimento para garantir um alinhamento a respeito do que cada tag significava.

Ainda para auxiliar nesse processo de tagueamento, a cada encontro, o grupo revia um documento compartilhado que, não só listava cada uma das tags, mas também dava uma breve descrição de elementos ou questões que constituíam tal categoria temática. Assim, foi possível, a todo momento desse processo, rever as etiquetas propostas pelo grupo, bem como recuperar o sentido de cada uma delas.

Essa etapa foi acompanhada da reafirmação tanto do esforço coletivo quanto do processo criativo na pesquisa, porque nela emergiram questões atinentes à pesquisa-matriz que foram se relançando a cada vez que uma tag era criada. Do mesmo modo, as leituras dos artigos eram ressignificadas a cada tag criada, e assim os pesquisadores encararam a tarefa de refazer suas fichas sempre que a discussão acerca das tags exigia modificar seu sentido. Um exemplo, foi a tag "Metodologias de Pesquisa" que fez com que fosse incluído o item 7 (metodologia de pesquisa utilizada) da ficha de leitura. Em certo momento, os pesquisadores exercitaram a apresentação do conteúdo dos seus fichamentos por meio da exposição das tags que eles usavam em suas fichas de leituras, demarcando que tais etiquetas serviam para categorizar as temáticas encontradas nos artigos, por meio de uma análise indutiva, como costuma acontecer em pesquisas qualitativas (NUNES et al., 2017).

Ao todo, nesta etapa da pesquisa bibliográfica, foram construídas 28 tags. São elas: Autores; Circulação e mobilidade urbana; Colonização; Conceptualizações de cidade; Crianças e juventude na cidade; Drogas; Educação; Gênero; Grupo/Coletivo/Tribos urbanas; Indígenas; Individualismo/Capitalismo contemporâneo; Memória e tempo; Metodologias de pesquisa; Modelos de cidade/Modos de vida na cidade; Movimentos migratórios na cidade; Políticas de estado/Políticas públicas; Práticas de segregação/Exclusão; Produção de subjetividade; Produção do comum; Racismo; Religiosidade; Resistência inventiva; Saúde; Território; Violência urbana; Urbano e ou rural; Orgulho/Boa relação com a cidade; Produção cultural/Turismo.

3.3.3) $3^{\text {a }}$ Fase: Inserção das fichas de leituras em software e sumarização das questões debatidas 
Nesta última fase da pesquisa bibliográfica, todos os fichamentos (bem como os textos dos quais decorreram os fichamentos) já eram da biblioteca virtual grupo INTERVIRES e, então, os 107 fichamentos foram inseridos no programa Atlas.ti. O Atlas.ti é um software que está entre os mais usados em pesquisa qualitativa. $\mathrm{O}$ uso de softwares nas pesquisas qualitativas serve, basicamente, para - por meio do uso da tecnologia - efetuar tarefas que, há anos, os pesquisadores têm feito de forma manual. Tal recurso economiza o tempo dos pesquisadores e pode facilitar o estoque de informação, bem como o gerenciamento e a recuperação de dados (NUNES et al., 2017). Desta forma, o uso do software se alinhou ao interesse de organizar os dados encontrados na pesquisa bibliográfica, de modo a facilitar a recuperação dos mesmos por meio das tags criadas coletivamente para, no futuro, favorecer a construção de revisões de literatura, por exemplo.

É de fundamental importância destacar que o uso de um software, neste caso, não simplificou o processo de pesquisa (ignorando a complexidade dos dados obtidos), muito menos tornou este processo mecanizado. O software foi utilizado como uma estratégia para organização de grande volume de informações e conteúdos, não sendo prioritariamente usado como forma de analisar os resultados da pesquisa. O uso do Atlas.ti deu maior sentido à construção das tags. E, embora o programa não tenha sido usado para construção de análise de dados, por meio do software, pôde-se facilmente visualizar a sobreposição de temas encontrados nos artigos lidos.

Por fim, o uso do programa facilitou um processo de sumarização da pesquisa bibliográfica, permitindo que fosse feito um rápido apanhado dos temas que o grupo discutiu ao longo de todo o processo. Ele permite, assim, recuperar, em poucos cliques, respostas encontradas para o problema de pesquisa, que norteou o processo de investigação traçado e vivenciado coletivamente no grupo INTERVIRES.

\section{Inventando, ainda, um modo de concluir}

A pesquisa bibliográfica aqui descrita descente de uma pesquisa-matriz que fomentou a busca sistemática por artigos que versavam sobre um tema específico: cidade e processos de subjetivação. Para rastrear a literatura atual referente ao tema e aprofundar as compreensões do coletivo interdisciplinar de pesquisadores acerca dos conteúdos foram criadas e seguidas quatro etapas distintas de pesquisa bibliográfica e organização dos estudos. Na primeira, foram estabelecidas as bases de dados para buscar escritos científicos, escolhidos descritores e feita a busca de artigos, considerando tais descritores em correlações decididas pelo grupo. $\mathrm{Na}$ segunda etapa, foi desenvolvida e posta em prática uma forma de filtrar os artigos encontrados. $\mathrm{Na}$ terceira etapa, foi realizada a leitura de todos os artigos selecionados e foram construídas tags, que serviram como códigos para alimentar (junto com fichamentos dos textos) um software reconhecidamente útil às pesquisas qualitativas.

Dito assim, parece um processo fácil e simplificado. Aparentemente, o processo foi conduzido como a execução diante de uma receita de bolo, que pode se estabelecer como um modelo. No entanto, jaz neste texto um processo complexo, que transborda os procedimentos exigidos em um resumo de um parágrafo. Em todas as etapas sumariamente descritas, os 
pesquisadores inventaram modos de fazer pesquisa, guiados pelos pressupostos da cartografia - que ao contrário de se valer de buscas sistemáticas, vale-se de um peculiar modo de estar atento (KASTRUP, 2015a). Inventar tem sempre um resultado imprevisível (KASTRUP, 2015b). Ao iniciar sua aventura metodológica, o grupo INTERVIRES não podia precisar onde chegaria, mas sabia que deveria encontrar/criar um modo de estudar, aprofundar compreensões, rastrear produções existentes que fizesse eco a seu modo rizomático e singularizante de compor um processo de pesquisa.

Encharcado por uma visão de mundo, o grupo produzia-se a si mesmo a cada passo da pesquisa, dando novos sentidos a sua forma de trabalhar. O que poderia parecer, na experimentação desses procedimentos, apenas a reprodução de um modelo burocrático que registra o processo de pesquisa e enquadra o que nele é possível pensar, se estabelecia mais como uma proposta de compartilhar leituras e debates, descartar referências, ressaltar ideias outras, discordar, reconhecer pensamentos nas palavras de diferentes autores.

É certo que a memória dessa pesquisa bibliográfica foi uma primeira vivência do campo da pesquisa-matriz - pois aqui se entende que o campo não se limita a um território físico onde se conjugam pesquisadores e não-pesquisadores. O território do pensamento se constituiu também e concomitantemente um campo nessa pesquisa.

Também é certo que a experiência trouxe uma miríade de reflexões necessárias em cada etapa e imprescindíveis à finalidade da pesquisa. Indubitavelmente, a narrativa deste processo de pesquisa bibliográfica - a qual envolveu uma busca sistemática por conteúdo, em um grupo que costumava, somente, fazer revisões narrativas - coloca-nos no lugar de quem precisa falar não somente sobre como tal processo se procedeu, mas o que se procedeu em tal processo: “Conhecer é analisar" (CANGUILHEM, 2012, p. 1).

Se, como diz Kastrup (2015b, p. 142), “A invenção de si é, ao mesmo tempo, invenção de mundo", o grupo INTERVIRES inventou um mundo de formas de ler, um mundo de formas de armazenar o conhecimento adquirido, e também um mundo de formas de compartilhar o conhecimento produzido e de produzir um conhecimento antes impensado.

Mesmo que existam vários artigos de metodologia científica que estabeleçam os mais variados protocolos para os mais variados gostos, o que a experiência aqui narrada revela é que, mesmo diante do rigor de uma busca sistemática é possível processos de criação e de produção do comum. Mesmo no trabalho do mais rigoroso pesquisador, aquele que segue à risca as normas pré-estabelecidas, há um desvio (às vezes invisível) que toca a criação.

No processo do Grupo INTERVIRES, artigos, conceitos e trajetos de diferentes pesquisas já realizadas compuseram uma trama que, assim, como o tecido urbano, é feita de modos hegemônicos e contra-hegemônicos de operar; é feita de invenções, de repetições, de reproduções do modelo capitalista e de formas de resistência a ele. No grupo INTERVIRES, a busca sistemática e a pesquisa bibliográfica nesse molde, foram parte de um desvio do "protocolo de estudar sem protocolos". Foi interessante viver um modo de experimentação contínua, pautado numa busca baseada em procedimentos metodológicos que, em princípio, não pareciam comungar com o pensamento epistemológico do grupo. Com isso (e por isso), estavam imbrincados, em um mesmo processo, os procedimentos de pesquisa que o grupo recusa e os movimentos de pesquisa que o grupo, desde seu início, escolhe e acolhe. 
Experimentar "implica construir um modo de pesquisar que acolha a experiência que insiste em expressar a multiplicidade que nos constitui” (LAZZAROTTO, 2015, p. 101). Significa forçar o pensamento a se mover. Navegar em um campo em que as categorias não estão em questão. Dirigir-se à produção de mais inomináveis. Nesse sentido, "produzir é [...] constituir campos de possibilidades" (SCHEINVAR, 2015, p. 196).

A construção dos procedimentos dessa pesquisa bibliográfica e sua experimentação compõem uma narrativa que produziu pesquisadores e conhecimento em um processo indissociável. A partir dessa experiência relatada, abre-se um campo de possibilidades para a continuidade da pesquisa e para a criação de produções acadêmicas acerca do tema em sua complexidade. O desafio de voltar-se ao problema de pesquisa, nesse percurso, comprovou-se engendrado com o compromisso, implícito na produção de conhecimento, em debruçar-se sobre o problema do próprio processo de pesquisar.

\section{Referências}

BARROS, Regina de Benevides. Dispositivos em ação: o grupo. In: SILVA, André do Eirado; NEVES, Claudia Abbês Baeta; RAUTER, Cristina (org.). SaúdeLoucura: subjetividade: questões contemporâneas. São Paulo: Hucitec, n. 6, 1997. p. 183-191.

CANGUILHEM, Georges. O conhecimento da vida. Tradução de Vera Lúcia Avellar Ribeiro. Rio de Janeiro: Forense Universitária, 2012.

FERENHOF, Helio Aisenberg; FERNANDES, Roberto Fabiano. Desmistificando a revisão de literatura como base para redação científica: método SSF. Revista ACB: Biblioteconomia em Santa Catarina. Florianópolis, v. 21, n. 3, p. 550-563, ago./nov. 2016.

KASTRUP, Virgínia. Inventar. In: FONSECA, Tania Mara Galli; NASCIMENTO, Maria Lívia do; MARASCHIN, Cleci (org.). Pesquisar na diferença: um abecedário. Porto Alegre: Sulina, 2015a. p. 139-141.

KASTRUP, Virgínia. O funcionamento da atenção no trabalho do cartógrafo. In: PASSOS, Eduardo; KASTRUP, Virgínia; ESCÓSSIA, Liliana da (org.). Pistas do método da cartografia: pesquisa-intervenção e produção de subjetividade. Porto Alegre: Sulina, 2015b. p. 32-51.

LAZZAROTTO, Gislei Domingas Romanzini. Experimentar. In: FONSECA, Tania Mara Galli; NASCIMENTO, Maria Lívia do; MARASCHIN, Cleci (org.). Pesquisar na diferença: um abecedário. Porto Alegre: Sulina, 2015. p. 99-101.

LIMA, Telma Cristiane Sasso de; MIOTO, Regina Célia Tamaso. Procedimentos metodológicos na construção do conhecimento científico: a pesquisa bibliográfica. Revista Katálysis. Florianópolis, v. 10, n. esp., p. 37-45, 2007.

MARCONI, Marina de Andrade; LAKATOS, Eva Maria. Técnicas de Pesquisa. 6 ed. revista. São Paulo: Atlas, 2007.

MARIANO, Ari Melo; SANTOS, Maíra Rocha. Revisão da Literatura: apresentação de uma 
abordagem integradora. In: AEDEM International Conference: Economy, business and uncertainty: ideas for a European and Mediterranean industry policy? Itália, 4 e 5 set. 2017. p. 427-443.

MAURENTE, Vanessa Soares. Expressar. In: FONSECA, Tania Mara Galli; NASCIMENTO, Maria Lívia do; MARASCHIN, Cleci (org.). Pesquisar na diferença: um abecedário. Porto Alegre: Sulina, 2015. p. 107-109.

NUNES, Juliane Vargas et al. A pesquisa qualitativa apoiada por softwares de análise de dados: uma investigação a partir de exemplos. Fronteiras - estudos midiáticos. São Leopoldo, v. 19, n. 2, p. 233-244, maio/ago. 2017.

PASSOS, Eduardo; KASTRUP, Virgínia; TEDESCO, Silvia (org.). Pistas do método da cartografia: a experiência da pesquisa no plano comum. Porto Alegre: Sulina, 2014. v. 2.

PASSOS, Eduardo; BARROS, Regina de Benevides. A cartografia como método de pesquisa-intervenção. In: PASSOS, Eduardo; KASTRUP, Virgínia; ESCÓSSIA, Liliana da (org.). Pistas do método da cartografia: pesquisa-intervenção e produção de subjetividade. Porto Alegre: Sulina, 2015. p. 17-31.

PASSOS, Eduardo; KASTRUP, Virgínia; ESCÓSSIA, Liliana da (org.). Pistas do método da cartografia: pesquisa-intervenção e produção de subjetividade. Porto Alegre: Sulina, 2015.

SCHEINVAR, Estela. Produzir. In: FONSECA, Tania Mara Galli; NASCIMENTO, Maria Lívia do; MARASCHIN, Cleci (org.). Pesquisar na diferença: um abecedário. Porto Alegre: Sulina, 2015. p. 193-195.

\section{Notas}

${ }^{\text {i } B l o g ~ d o ~ g r u p o ~ d e ~ p e s q u i s a ~ I N T E R V I R E S: ~ h t t p s: / / w w w . u f r g s . b r / i n t e r v i r e s / . ~ A c e s s o ~ e m: ~} 20$ dez. 2018.

ii Trata-se de um projeto em andamento, financiado, que teve como disparador uma parceria firmada entre pesquisadores britânicos e brasileiros para investigar modos de subjetivação e as fronteiras urbanas de quatro cidades brasileiras. A pesquisa "Experiências Urbanas e Produção do Comum: modos de vida e invenção das cidades em tempos de intolerância" foi aqui designada como sendo a pesquisa-matriz, uma vez que a partir dela surgiram desdobramentos, incluindo a pesquisa bibliográfica relatada neste artigo, bem como outros projetos de diferentes programas de pós-graduação a ela vinculados. 